\title{
EFEK SAMPING RADIASI SINAR X DAN SINAR GAMMA PADA DAYA TAHAN RONGGA MULUT
}

\section{Hj. Barunawaty}

Bagian IImu Penyakit Mulut Fakultas Kedokteran Gigi

Universitas Hasanuddin

\begin{abstract}
The Radiation which usually use in the Medical World is the $X$-ray radiation and Gamma ray radiation. Both uses for radiodiagnostic and radiotheraphy, have same characteristic but from diffent well. $X$-ray source from $X$-ray equipmentwhichwork of art Human, whereas Gamma ray source from radioac-tive materialswhich to spout according spontaneous andnatu-ralcharacteristic. The use of ionizing radiation high dose which to use in radiotherapy possible to give sideeffect at defence oral component and others body eels which still healthy.
\end{abstract}

Key work : yadioation, immunology, oral cavity.

\section{PENDAHULUAN}

Radiasi yang sering

digunakan dalam dunia kedokteran adalah radiasi sinar $X$ dan radiasi sinar Gamma. Keduanya digunakan untuk keperluan diagnostik maupun terapi, mempunyai sifat yang sama tapi berasal dari sumber yang berbeda. Sinar $X$ berasal dari alat sinar $X$ yang merupakan hasil buatan mariusia, sedangkan sinar Gamma berasal dari bahan radioaktif yang dipancarkan secara spontan dan bersifat alamiah ${ }^{1}$

Radiobiologi merupakan ilmu yang mempelajari hubungan antswa aspek-aspek radiasi serta kelainan biologik yang ditimbulkannya.IImu ini berkembang mengikuti pasang surutnya terapi radiasi dan mulai 
dipelajari setelah diketahui bahwa sinar $X$ bukan hanya sebagai sarana diagnostik namun juga dapat menimbulkan efek biologis.

Penemuan ini telah membuka cakrawala baru di bidang pengobatan kanker dengan menggunakan radiasi. Kemajuan teknologi di bidang radiologi ini telah maju dengan pesat sekali, baik di bidang diagnostik maupun terapi. Banyak kelainan yang dulunya sulit didiagnosis, dewasa ini menjadi lebih mudah berkat kemajuan di bidang radiodiagnostik. Demikian juga banyak penyakit yang dulunya sulit untuk disembuhkan, sekarang ini dengan kemajuan dalam bidang disembuhkan, atau paling tidak masa hiduppenderita dapat dipeipanj ang. ${ }^{2}$

\section{TINJAUAN PUSTAKA}

Radiasi merupakan suatu proses pelepasan energi dari suatu obyek sebagai partikel atau gelombang. Radiasi yang berbentuk gelombang elektromagnetik mempunyai panjang gelombang sangat pendek. ${ }^{1,3}$
Radiasi biasanya dikelompokkan menjadi dua kelompok yaitu radiasi korspukuler dan radiasi elektromagnetik.Radiasi korpukuler disebut juga radiasi partikel yaitu suatu pancaran atau partikel subatom, yang mempunyai kemampuan untuk memindahkan energi kinetiknya ke beban yang ditembus yang termasuk radiasi korpuskuler atau radiasi alfa, radiasi elektron, negaton (partikel beta), radiasi touton dan radiasi neutron. Radiasi elektromagnetik mempunyai pancaran gelombang (gabungan muatan listrik dan magnetik) yang dapat menyebabkan perubahan struktur suatu bahan (media) yang dilalui, termasuk radiasi sinar $\mathrm{X}$ dan sinar Gamma. ${ }^{4}$

Radiasi yang dapat menghasilkan ion di dalam suatu media disebut radiasi pengion. Semua radiasi korpukuler termasuk radiasi pengion dan hanya beberapa radiasi elektromagnetik yang termasuk radiasi pengion sehingga kelompok elektromagnetik dapat dibagi menjadi dua kelompok besar yaitu : pertama, radiasi 
dengan panjang gelombang yang sangat pendek, kurang dari 100 Ao dapat menghasilkan pasangan ion bila radiasi ini berinteraksi dengan suatu medium. Kedua, radiasi yang mempunyai panjang gelombang relatif panjang (100 Ao atau lebih) tidak menghasilkan pasangan ion bila berinteraksi dengan suatu medium. Radiasi elektromagnetik yang dapat menyebabkan ionisasi antara lain adalah sinar $X$ dan sinar Gamma, sedangkan radiasi elektromagnetik yaitusinar yang tampak oleh mata manusia adalahgelombang televisi. $^{1}$

\section{SIFAT-SIFAT RADIASI}

Menurut beberapa penulis, sifatsifat radiasi adalah sebagai berikut $^{3,5,7}$

- Tidak dapat dideteksi dengan panca indera

- Tidak dapat dibelokkan dengan medan magnet

- Mempunyai massa tetapi tidak mempunyai muatan positif

- Tidak dapat difokuskan dengan lensa apapun

- Dapat dibelokkan setelah menembus logam atau benda padat

- Mempunyai panjang gelombang sangat pendek0,1 - 0,5 atau 0,001-0,005 mm

- Kecepatan rambatnya sama dengan kecepatan rambat cahaya (3x108 m/detik)

- Tidak dapat difokuskan pada satu titik

- Dapat menembus benda yang dilaluinya

- Dapat diserap oleh timah hitam (pb)

- Dapat menimbulkan perbendaraan atau fluorersense pada subtansi tertentu seperti intensifying screen

- Dapat mengionisasikan gas dengan mengeluarkan elektron dari atom dan membentuk ion yang dapat digunakan untuk pengukuran radiasi atau dengan alat kamar radiasi

- Dapat menimbulkan efek biologis sebagai akibat radiasi ionisasi

- Dapat bereaksi dengan emulsi halida perak pada film radiografis untuk keperluan 
radio-diagnostik.

MANFAAT RADIASI

Berdasarkan

sifat-sifat

tertentu dari radiasi dapat diperoleh

manfaat yang dapat digunakan dalam dunia kedokteran antara lain: $:^{4,7,8}$

- Membuat rontgenogram untuk keperluan radiodiagnostik Terapi radiasi pada penyakit keganasan tertentu

- Membuat xeroradiografi

- Untuk keperluan dibidang industri (pengawetan makanan kaleng), dibidang pertanian dan biologis (menciptakan bibit unggul)

\section{BAHAYA RADIASI}

Adapun bahaya atau sifat radiasi pengion yang merugikan antara lain : ${ }^{35}$

- Dapat menimbulkan penurunan daya tahan tubuh yang menyebabkan komponen pertahanan rongga mulut terhadap kolonisasi bakteri dan jamur meningkat.

- Dapat menimbulkan efek biologis tidak hanya terhadap sel-sel kanker, tetapi juga terhadap selsel tubuh yang masih sehat

- Oleh karena tidak dapat dilihat oleh panca indera, maka orang yang terkena radiasi ionisasi tidak menyadari bahaya radiasi tersebut

- Tidak dapat difokuskan pada daerah yang akandisinari

- Efeknya pada tubuh tidak segera terlihat (efektertunda) dan bersifat kumulatif

\section{PEMBAHASAN}

Panggunaan radiasi pengion dosis tinggi yang digunakan pada terapi radiasi dapat berpengaruh pada sel-sel tubuh yang masih sehat, karena tubuh manusia tidak dapat dilindungi sepenuhnya dari sinar radiasi baik sinar terapi radiasi maupun radiasi sinar radio diagnostik. Sebagian dari energi radiasi akan diserap oleh tubuh manusia, sehingga dapat menimbulkan efek biologis pada sel tubuh yang masih hidup. ${ }^{9}$

Secara umum, perubahan jaringan atau sel yang terkena radiasi sinar $X$ sebagai akibat 


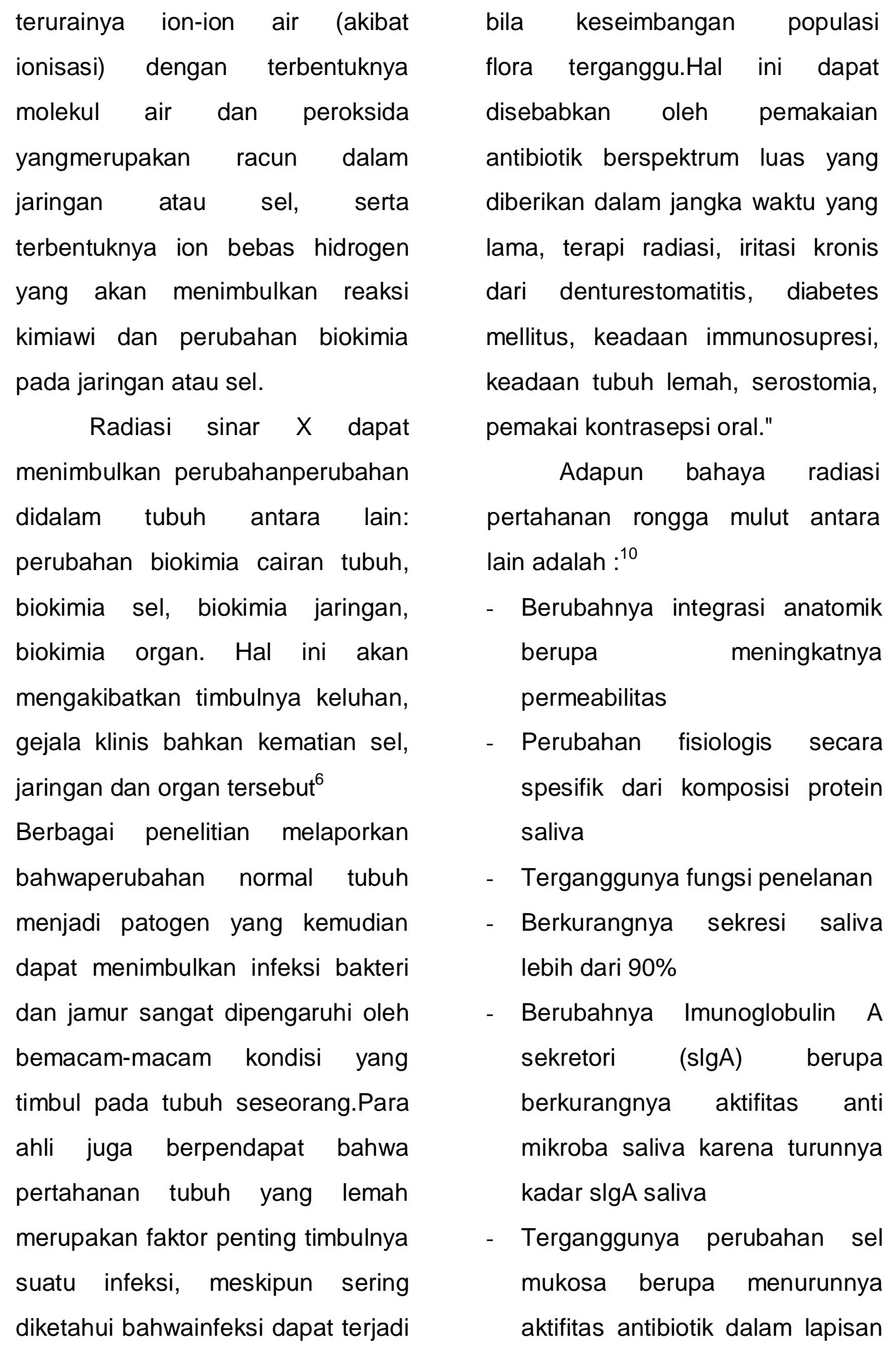


basal

- Berubahnya flora didalam mulut, sehingga memungkinkan jasad renik yang patogen berkembang

\section{KESIMPULAN}

Sinar $X$ dan sinar Gamma merupakan alat yang dapat digunakan sebagai radiodiagnostik dan radioterapi

Baik radiodiagnostik dan radioterapi dapat menimbuikan aspek-aspek radiasi serta efek biologis pada jaringan yang masih sehat

- Terapi radiasi dapat juga menyebabkan komponen pertahanan rongga mulut terhadap kolonisasi bakteri dan jamur menurun

\section{SARAN}

Disarankan sebelum penderita mendapatkan perawatan radiodiagnostik dan radioterapi sebaiknya diberikan suatu alat/obat pencegahan agar efek-efek kumulatif yang akan timbul dapat dicegah, minimal dapat mengurangi tingkat keparahannya.

\section{DAFTAR PUSTAKA}

1. Amsyari F., 1989. Radiasi Dosis Rendah dan Penyegahannya Terhadap Kesehatan. Airlangga Univercity Press. Surabaya. Him. 1-2,19.

2. Susworo dan Daniel, 1987. Karsinoma Nasofaring, Aspek Radiodiagnostik dan Radioterapi. Balai penerbit Fakultas Kedokteran Universitas Indonesia. Him. 3-langland

3. O.E., Shippy PH., Langlais R.P, 1989. Text Book Of Dental Radiology, Ed. Ke-2., Chales C Thomas Publisher., Springfield Illinois. Him. 50.

4. Herman C, 1987. Pengantar Fisika Kesehatan, Ed. Ke-2. Pengaman press, New York, Ox- ford Toronto. Him. 87.

5. Frommer H.H., 1981. Radiologic In Dental Practice. The CV. Mosby Compony St. LouisToronto-London. Him. 1-24.

6. Widjaja E.D., 1988.Radioterapi, Ed. Ke-3. PT. Dian Rakyat, Jakarta. Him. 16-18...

7. Lukman D., 1991. Dasar-Dasar Radiologi Dalam IImu 
Kedokteran Gigi, Ed. Ke-2. Widya Medika Jakarta. Him. 1 24.

Toronto-montreal SydneyTokyo. Him. 7-13.

10. Frederik K.L.S., 1996. Makositis

8. BATAN, 1985. Pedoman Akibat Radiasi, Pencegahan dan Proteksi Radiasi di Rumah Sakit Pengobatan (Irradiation dan Tempat Praktek Umum Lainnya. Ed. Ke-1. Badan Tenaga Atom Nasional, Jakarta. Him 1-10. Mucositis, Prevention and Treatment). Ed. Ke-1. Widya medika, Jakarta. Him. 4-8.

11. BoyandR.E, 1995. Basic Medical

9. Kumar V., Cotram R.S., Robbins. S. L., 1992. Basicpathology. Ed. Ke-5. W. B. Saunders Compony, LondonMicrobiology. Ed. Ke-5. Little Brown and Compony, Boston New York Toronto London. Him. 485-486. 